\title{
LETTERS
}

\section{An old-new problem: alcohol use among medical students}

Comments from Brian Owens' recent CMAJ news article $^{1}$ on medical students' excessive drinking and the new National Wellness Program of the Canadian Federation of Medical Students should be widely heeded.

Nearly 50 years ago, the first scientific reports on alcohol drinking among medical students were published. In a 1971 survey of 749 medical students at the University of Glasgow that was published in BMJ, McKay and colleagues reported that half of the students regularly drank alcohol. Twenty-two percent of the students who regularly drank alcohol also took drugs. The final sentence of the study was, "This report may present problems for the subjects, for the investigators, for the University, and not least for the community, but the urgent need for an appraisal of its public and professional implications constitutes the overriding consideration."

A further investigation by Herity and colleagues involving 753 medical students at the University College Dublin during the academic years 1972/73 and 1973/74 also found excessive alcohol consumption among students. ${ }^{3}$ Seventy-five percent of the students regularly drank alcohol, and the authors observed that the prevalence of alcohol consumption increased significantly during the years of study (first year 63\%, third year $77.5 \%$ and fourth year $88.6 \%$ ). They also found that use of psychoactive drugs by medical students was also significantly associated with alcohol consumption. Possible higher rates of excessive drinking patterns in medical students compared with their peers in the general population was shown in studies in subsequent years. ${ }^{4-7}$

In 1983, Gardner and colleagues reported that increased communication from significant others and social support had a protective effect on the behaviour of students who consumed alcohol during the first 3 months of medical school. ${ }^{8}$ It has been 30 years since the first results about the good therapeutic efficacy of prevention and intervention programs for alcohol use disorder in medical schools were discussed. ${ }^{5,9}$

The existing temporal presence of the link between alcohol and medical students makes it clear that intervention programs like the one offered by Canadian Federation of Medical Students should find societal support and are best associated with volitional self-observation training to promote the students' competence in implementation planning and intention shielding.

\section{Martin Hofmeister PhD}

Nutrition scientist, Department of Food and Nutrition, Consumer Centre of the German Federal State of Bavaria, Munich, Germany

Cite as: CMAJ 2019 February 11;191:E170. doi: $10.1503 /$ cmaj. 71147

\section{References}

1. Owens B. Growing concern over medical students excessive drinking. CMAJ 2018;190:E1215.

2. McKay AJ, Hawthorne VM, McCartney HN. Drug taking among medical students at Glasgow University. BMJ 1973;1:540-3.

3. Herity BA, Horgan JM, Bourke GJ, et al. Tobacco, alcohol and other drug use among medical students. Ir Med J 1977;70:532-9.

4. Thomas RB, Luber SA, Smith JA. A survey of alcohol and drug use in medical students. Dis Nerv Syst 1977;38:41-3.

5. Clark DC, Eckenfels EJ, Daugherty SR, et al. Alcoholuse patterns through medical school: a longitudinal study of one class. JAMA 1987;257:2921-6.

6. Collier DJ, Beales IL. Drinking among medical students: a questionnaire survey. BMJ 1989; 299:19-22.

7. Keller S, Maddock JE, Laforge RG, et al. Binge drinking and health behavior in medical students. Addict Behav 2007;32:505-15.

8. Gardner R Jr, Wilsnack SC, Slotnick HB. Commu nication, social support and alcohol use in firstyear medical students. J Stud Alcohol 1983;44: 188-93.

9. Clare AW. The alcohol problem in universities and the professions. Alcohol Alcohol 1990;25: 277-85.

Competing interests: None declared. 